\title{
RESULTS FROM A
}

MAMMOGRAPHY AUDIT AND PATIENT ATTITUDES
STUDY AT THE PRINCESS MARGARET HOSPITAL

By Solange Payne \& Leander Farrington

Department of Radiology, Princess Margaret Hospital, Nassau

https://doi.org/10.15362/ijbs.v13i0.60

\section{ABSTRACT}

This paper reports the results from (1) a mammography audit from the Princess Margaret Hospital and (2) patient attitudes towards mammograms in the context of national risks of breast cancer. The audit allows for the quality of mammographic diagnoses to be assessed. Information on patient attitudes and follow-up to mammograms is required so that health care providers can better interact and educate patients. Between 2000 and 2002, about two percent of 4,322 patients were diagnosed with breast cancer. A family history, previous mastectomy, or a patient having a complaint were found to elevate the risk of breast cancer. In the telephone study, the cancer detection rate was 18.8 per 1000. The positive predictive value of mammogram reports was $15.4 \%$, the recall rate was $12.2 \%$. The biopsy yield was $32.1 \%$. The sensitivity and specificity of mammograms in 2001 were $100 \%$ and $89.5 \%$ respectively. The telephone study of 1,092 previous patients found that doctors were a major influence in getting patients to have a mammogram. Many women were ignorant about essential aspects of mammography and this probably resulted in many of them not returning for subsequent mammograms. Patients who should have had follow-up appeared not to have followed the doctor's recommendation. National data on breast cancer indicated that women in New Providence have a higher risk of breast cancer compared to women in other Bahamian islands. 
In 2000, breast cancer was the leading cause of death by any cancer in women. It was the seventh leading cause of death amongst women in The Bahamas. Overall, it accounted for almost four percent of all deaths in women in 2000. Nationally, breast cancer was the fourteenth leading cause of death and prostatic cancer the twelfth in 2000 (Health Information and research Unit, Ministry of Health, 2001a). In 2000, the incidence rate was 28.2 per 100,000 and the mortality rate associated with breast cancer was 17.8 per 100,000 (Health Information and Research Unit, Ministry of Health, 2001b). When age specific rates are considered, it was clear that breast cancer mortality is higher among "younger" rather than "older" women. In the 45-64 year age group, it was the third leading cause of death amongst females, and in the 65+ group only the fifth leading cause. This compares with prostatic cancer which is not in the top ten leading causes of death in the $45-64$ year age group but is the second leading cause of death in the 65+ age group. (Health Information Unit and Research Unit, 2001b and 2002c). So clearly, breast cancers are a major cause of death in The Bahamas.

Because cancer related deaths can be prevented if cancers are detected early enough, mammography is key to reducing the mortality associated with breast cancer. In addition to the personal suffering caused, cancer patients are a major financial strain on the health services. In 2000, breast cancer was the leading cause of cancer inpatient morbidity at Princess Margaret Hospital (Health Information and Research Unit, 2002c).

Mammography has attracted considerable media attention worldwide, particularly with regard to how effective mammography screening might be and when and how often patients should have mammograms (for example: Early breast screening 'saves lives', 2003). Considerable media space has been devoted to mammography in the local media (e.g. Life Force (2003), What Bahamian women should know about Breast Cancer (2003) and October was designated breast cancer awareness month in association with the UN).

In 1999, as a result of the Mammography Awareness Initiative, the Hospital obtained a new mammography machine and mammography suite. This allowed the Hospital to offer a limited screening programme in addition to its diagnostic service. Other health care providers also provide mammography screening and screening has become part of the health care offered under employee health insurance schemes, and this has increased the demand for mammograms.

In The Bahamas, there appear to have been two published studies on breast self examination (Dean, 1985 and Mackey, 2001) which considered how often women examine their breasts and the reasons they do or do not do so. These studies interviewed less than 200 women and focused on knowledge and attitudes towards breast cancer.

The purpose of this paper was twofold: (1) to make an audit of the mammography service at Princess Margaret Hospital and (2) assess attitudes and actions towards mammograms of previous patients. The audit allows us to assess how well mammograms are read, but the data also allow other aspects relating to mammography and breast cancer to be assessed. The essential methodology 
behind this mammography audit follows that described by Linver et al. (1995) and Linver (1997), which addresses the requirements for a mammography audit as stated by the Federal Drug Administration in America. The audit allows the administration of patient records and follow-up to be evaluated as well as assessing the reliability of the screening process.

Patient data also allow known risk factors such as age, family history and previous mastectomy (American Cancer Society, 2004) to be evaluated in The Bahamian context. Because environmental effects (Shiels, 2002) as well as occupation (BBC, 2001) can influence breast cancer rates, we need to be aware of any environmental factors which may be present within The Bahamas. Therefore, possible variations in breast cancer rates within New Providence and nationally were examined.

\section{MATERIALS \& METHODS}

Four sources of data were utilized in this study. Data from the Mammography Unit were used to identify the numbers of mammograms and their diagnoses. These records also included information about the patient's family history and age. This information is referred to as the "audit" data. The time period included in this study, 2000 to 2002, represents the first three full years of operation of the mammography initiative at Princess Margaret Hospital.

In order to assess the reliability of the doctor's diagnosis of the mammogram, and in particular, to assess the number of false negatives, a telephone census was attempted of all patients who had had a mammogram in 2001, at the end of 2002 and the beginning of 2003, i.e. approximately one year after the mammograms were read. (False negatives are defined to be those which are found to be positive within one year of the mammogram, Linver et. al., 1995). Patients contacted in the telephone survey were asked for their permission to be included in the study and they were assured that any information they provided would be confidential.

The reliability of the diagnosis from the mammogram can also be assessed from histology data. It is recognized that not all patients who had a mammogram at Princess Margaret Hospital may have had their histology tests done there, so matches of histology to mammogram diagnosis is only possible for a subset of patients.

Variations in breast cancer rates examined using the telephone study (variations within New Providence) and national data on breast cancer were used to look at the mortality of breast cancer nationwide (Health Information and Research Unit, 2002a, 2002b, 2003a, 2003b).

Summary statistics were generated using SPSS. Odds ratios were calculated to assess the relative risk of one group against another. Odds ratios provide an approximate relative risk estimate when the groups have been defined retrospectively (usually after a particular outcome), rather than before the outcome is observed (Altman, 1991). (When the confidence limits of the odds ratio includes one, the risks associated with the two groups are considered similar.) Standardized mortality ratios (Altman, 1991) associated with beast cancer were provided by the Ministry of Health specially for this study. These ratios 
allow for age differences when estimating mortality ratios between groups with varying age structure.

\section{RESULTS}

\section{AUDIT DATA}

Data were obtained on 1,233 patients in 2000, 1,461 in 2001 and 1,628 in 2002. This represents a 32\% increase in mammography patients from 2000 to 2002 (Figure 1). Due to the mammography records being incomplete for some patients, the numbers of observations for certain assessments are less than these numbers of patients. For clarity of presentation, outcomes such as ultrasound, biopsy, ductogram etc, were classified as indeterminate.

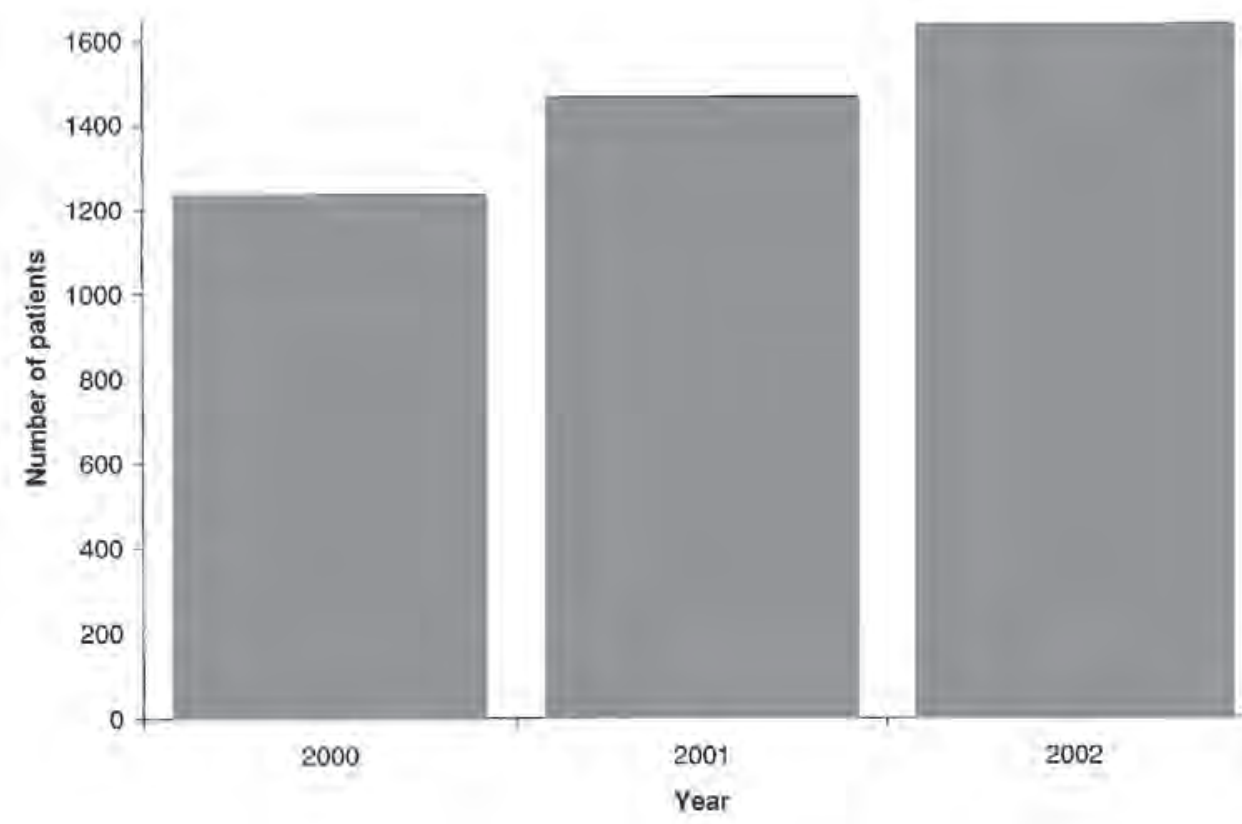

Figure 1: Number of patients having mammograms at the Princess Margaret Hospital, 2000-2002.

In 2000, the average time since a patient had a previous mammogram was 2.69 years (se $=0.17$ ), in 2001 it was 2.26 years ( $\mathrm{se}=0.12$ ) and in 2002 it was 2.05 years (se $=0.01$ ). Of all patients each year, the percentage of those who could not say when they had had a previous mammogram (i.e. probably coming for a mammogram for the first time) fell from $64 \%$ in 2000 to $60 \%$ in 2002 . This suggests that more people are returning for mammograms than before (Table 1). 
Table 1: Description of patients who had a mammogram in 2000, 2001 and 2002 at Princess Margaret Hospital.

\begin{tabular}{|l|l|l|l|}
\hline Previous mammogram & $\mathbf{2 0 0 0}$ & $\mathbf{2 0 0 1}$ & $\mathbf{2 0 0 2}$ \\
\hline $\begin{array}{l}\text { Percentage of patients not giving a date for } \\
\text { a previous mammogram: }\end{array}$ & $64 \%$ & $61 \%$ & $60 \%$ \\
\hline $\begin{array}{l}\text { Percentage of patients giving a date for a } \\
\text { previous mammogram }\end{array}$ & $36 \%$ & $39 \%$ & $40 \%$ \\
\hline $\begin{array}{l}\text { Mean age of patients not giving a date for a } \\
\text { previous mammogram }\end{array}$ & $\begin{array}{l}49.3 \\
\text { se:0.47 }\end{array}$ & $\begin{array}{l}50.6 \\
\text { se:0.42 }\end{array}$ & $\begin{array}{l}51.64 \\
\text { se:0.41 }\end{array}$ \\
\hline $\begin{array}{l}\text { Mean age of patients giving a date for a } \\
\text { previous mammogram }\end{array}$ & $\begin{array}{l}52.6 \\
\text { se:0.52 }\end{array}$ & $\begin{array}{l}54.3 \\
\text { se:0.45 }\end{array}$ & $\begin{array}{l}54.0 \\
\text { se:0.44 }\end{array}$ \\
\hline $\begin{array}{l}\text { Percentage of all patients having a } \\
\text { mammogram in previous three years }\end{array}$ & $26 \%$ & $29 \%$ & $32 \%$ \\
\hline $\begin{array}{l}\text { For those patients having a previous } \\
\text { mammogram: Percentage of patients who } \\
\text { had had a previous mammogram and had } \\
\text { a mammogram in previous three years }\end{array}$ & $71 \%$ & $75 \%$ & $80 \%$ \\
\hline $\begin{array}{l}\text { No. of patients having a previous } \\
\text { mammogram: }\end{array}$ & 444 & 568 & 653 \\
\hline \begin{tabular}{l} 
Total number of observations: \\
\hline
\end{tabular} & 1233 & 1461 & 1626 \\
\hline
\end{tabular}

From Table 1 it is apparent that more patients who had previous mammograms are returning in 2002 than 2000 (Table 1). The average age of patients in 2000 was 50.5 years (se=0.36), in 200152.0 years (se=0.32) and 52.6 years (se $=0.30$ ) in 2002. The most commonly reported reason for having a mammogram was "routine", but in most cases, no reason was recorded (Table 2).

Table 2: Reasons for patients presenting for a mammogram at Princess Margaret Hospital, Nassau. Percentages of patients within each of the years, 2000 to 2002.

\begin{tabular}{|l|c|c|c|}
\hline & $\mathbf{2 0 0 0}$ & $\mathbf{2 0 0 1}$ & $\mathbf{2 0 0 2}$ \\
\hline Complaint & 19 & 12 & 9 \\
\hline Poutine & 18 & 20 & 21 \\
\hline Discharge & 8 & 8 & 7 \\
\hline Previous mammogram & 1 & 2 & 2 \\
\hline Not recorded & 1 & 2 & 60 \\
\hline Number of patients & 52 & 56 & 1628 \\
\hline
\end{tabular}


The outcome of the mammogram, as reported by the doctor, is given in Table 3 . About $2 \%$ of the patients were reported as probably malignant in each year, and about $80 \%$ had normal or benign findings. Twelve to fifteen percent of patients were indeterminate cases, i.e. they needed additional studies.

Table 3: Doctor's report of mammograms at the Princess Margaret Hospital, Nassau as a percentage of all mammograms with the years 2000 to 2002.

\begin{tabular}{|l|c|c|c|}
\hline & $\mathbf{2 0 0 0}$ & $\mathbf{2 0 0 1}$ & $\mathbf{2 0 0 2}$ \\
\hline Normal & 44 & 57 & 64 \\
\hline Benign & 34 & 30 & 15 \\
\hline Indeterminate & 15 & 8 & 12 \\
\hline Probably malignant & 3 & 2 & 2 \\
\hline Not recorded & 5 & 3 & 6 \\
\hline Number of patients & 1,233 & 1,461 & 1,628 \\
\hline
\end{tabular}

The percentage of patients who had blood relatives with breast cancer was $25.6 \%$ in $2000,24.0 \%$ in 2001 and $23.4 \%$ in 2002 . The percentage of patients who had had a mastectomy was $6.4 \%$ in $2000,4.9 \%$ in 2001 and $4.6 \%$ in 2002.

\section{Incidence of breast cancer}

Reason for the examination by the mammographic diagnosis was noted for 621 patients in 2001 (Table 4). Of the 314 patients who came because of a previous mammogram or a routine examination, $0.96 \%$ were diagnosed as being probably malignant, of those coming with any other reason, $4.56 \%$ were diagnosed as being probably malignant. Therefore there is a significantly higher risk ( $\mathrm{p}<0.05$ ) (odds ratio: 4.95, 95\% confidence limits:1.41-17.4) of diagnosing malignancy if the patient presents with a complaint or pathology.

Table 4: Frequency of reason for examination by mammographic examination diagnosis of 621 examinations at Princess Margaret Hospital in 2001.

\begin{tabular}{|c|c|c|c|c|c|}
\hline \multirow{2}{*}{$\begin{array}{l}\text { Reason for } \\
\text { examination }\end{array}$} & \multicolumn{5}{|c|}{ Diagnosis } \\
\hline & Total & Normal & $\begin{array}{l}\text { Probably } \\
\text { benign }\end{array}$ & Indeterminate & $\begin{array}{l}\text { Probably } \\
\text { malignant }\end{array}$ \\
\hline Complaint & 171 & 110 & 41 & 18 & 2 \\
\hline Discharge & 23 & 7 & 6 & 9 & 1 \\
\hline $\begin{array}{l}\text { Previous } \\
\text { mammogram }\end{array}$ & 24 & 13 & 9 & 2 & \\
\hline Pathology & 113 & 49 & 33 & 20 & 11 \\
\hline Routine & 290 & 168 & 91 & 28 & 3 \\
\hline Total & 621 & 347 & 180 & 77 & 17 \\
\hline
\end{tabular}

The mean ages of patients associated with the outcome of the mammogram are given in Table 5 for each year. In each year, patients associated with malignancy had a mean age in the mid-fifties. Overall, the mean ages at which the outcome was diagnosed as indeterminate or malignant were significantly 
higher $(\mathrm{p}<0.05)$ than those for the other two outcomes. In the case of malignant diagnoses, the age of the youngest patients in whom this was diagnosed was 33, 34 and 29 in 2000, 2001 and 2002 respectively. The corresponding oldest ages were 80, 77 and 91 . Only one of these three young people diagnosed with cancer reported a family history of breast cancer.

Table 5: Relationship between age and outcome of mammogram, 2000 to 2002

\begin{tabular}{|l|c|c|c|c|}
\hline & $\mathbf{2 0 0 0}$ & $\mathbf{2 0 0 1}$ & $\mathbf{2 0 0 2}$ & Overall \\
\hline Normal & 49.9 & 51.5 & 52.2 & 51.4 \\
& se: 0.50 & se:0.42 & se: 0.38 & se $: 0.25$ \\
\hline Benign & 50.4 & 52.5 & 53.0 & 51.6 \\
& se: 0.62 & se $: 0.56$ & se $: 0.66$ & se $: 0.35$ \\
\hline Indeterminate & 54.2 & 52.9 & 52.4 & 53.2 \\
& se $: 1.24$ & se $: 1.08$ & se $: 1.16$ & se $: 1.16$ \\
\hline Malignant & 56.4 & 54.4 & 57.9 & 56.4 \\
& se $: 2.01$ & se $: 2.47$ & se $: 2.65$ & se: 1.39 \\
\hline
\end{tabular}

Risk factors associated with breast cancer

Patients were also classified by their family history, with respect to blood relatives having been diagnosed with breast cancer. The combined data from the three years, 2000 to 2002, are presented in Table 6. With no family history $2.09 \%$ of patients were diagnosed with malignant tumors compared with $3.04 \%$ of patients with a family history. While the risk of having breast cancer is increased (odds ratio is 1.47), the result does not attain formal significance, probably due to the small sample size, however the probability level of $\mathrm{p}<0.10$ is sufficiently close to formal significance $(\mathrm{p}=0.05)$ not to be overlooked. In the case of indeterminate diagnosis, although the odds ratio is only 1.26 , this increase is clearly associated with family history $(\mathrm{p}<0.05)$.

Table 6: Relationship between family history and outcome of mammogram and the associated odds ratio, for the period 2000 to 2002.

\begin{tabular}{|c|c|c|c|}
\hline Normal & $\begin{array}{c}\text { No reported } \\
\text { family history } \\
1784 \\
\end{array}$ & $\begin{array}{c}\text { Reported } \\
\text { family history } \\
518 \\
\end{array}$ & $\begin{array}{l}\text { Odds ratio due } \\
\text { to family history }\end{array}$ \\
\hline Benign & 711 & 259 & \\
\hline Indeterminate & 454 & 180 & $\begin{array}{c}1.26 \\
(95 \% \text { CLs: } 1.04,1.52)\end{array}$ \\
\hline Malignant & 63 & 30 & $\begin{array}{c}1.47 \\
(90 \% \text { CLs: } 1.01,2.12)\end{array}$ \\
\hline $\begin{array}{l}\text { Total number } \\
\text { of patients }\end{array}$ & 3012 & & 987 \\
\hline
\end{tabular}

CL: Confidence limits of the Odds ratio

The median ages of the patients diagnosed with malignant tumors and who had a family history of breast cancer were consistently lower than patients without a stated family history (Table 7). 
Table 7: Median ages of patients diagnosed with a malignant cancer, with and without a stated family history of breast cancer, between 2000 and 2002.

\begin{tabular}{|c|c|c|}
\hline Year: & $\begin{array}{c}\text { No reported } \\
\text { family history }\end{array}$ & $\begin{array}{c}\text { Reported } \\
\text { family history }\end{array}$ \\
\hline $\mathbf{2 0 0 0}$ & 60.5 & 59 \\
\hline $\mathbf{2 0 0 1}$ & 58 & 47 \\
\hline $\mathbf{2 0 0 2}$ & 53 & 49 \\
\hline
\end{tabular}

Patients were also classified by any history of a previous mastectomy. The combined data from the three years, 2000 to 2002, are presented in Table 8. The risk of being diagnosed with breast cancer with or without a previous mastectomy varied from $4.41 \%$ to $2.04 \%$, indicating a significant increase in the risk $(\mathrm{p}<0.05)$, Table 8 .

Table 8: Relationship between a previous mastectomy and outcome of mammogram and the associated odds ratio, for the period 2000 to 2002.

\begin{tabular}{|l|c|c|c|}
\hline & $\begin{array}{c}\text { No previous } \\
\text { mastectomy }\end{array}$ & $\begin{array}{c}\text { Previous } \\
\text { mastectomy }\end{array}$ & $\begin{array}{c}\text { Odds ratio due to } \\
\text { previous mastectomy }\end{array}$ \\
\hline Normal & 2170 & 131 & 39 \\
\hline Benign & & 925 & 0.74 \\
\hline Indeterminate & 601 & 25 & $\begin{array}{c}\text { (90\% CLs: } 0.5,1.06 \\
\text { Malignant }\end{array}$ \\
\hline $\begin{array}{l}\text { Total number } \\
\text { of patients }\end{array}$ & 3773 & 204 & (95\% CLs: $1.09,4.46)$ \\
\hline
\end{tabular}

CLs: Confidence limits for the odds ratio

\section{Histology correlation}

At Princess Margaret Hospital, 181 histology reports were available for patients referred as a result of a suspicious mammogram. The patients' ages ranged from 11-86 with a mean age of 46.2 (se: 1.31) years. Forty-seven patients who had mammograms in 2001 also had histology reports. Thirty-four patients had had their histology in 2001 and the remainder in 2002. Overall, of the 175 histology reports in 2001, 40, or $22.9 \%$ also had a mammogram report (which might not necessarily have been within the last year). In 2002, of 158 histology patients, $43 \%$ also had a mammogram.

Where patients had had a mammogram and a histology report, the results of the two procedures were compared for 2001 (Table 9)). Patients who were known to have had a mammogram a year or more before the histology were omitted from these comparisons. 
Table 9: Association between mammography and histology reports for patients having mammograms at the Princess Margaret Hospital in 2001. (Number of patients)

\begin{tabular}{|l|c|c|c|c|}
\hline Mammography Report & \multicolumn{4}{|c|}{ Histology Report } \\
\hline & Benign & In situ & Invasive & Normal \\
\hline Benign & 7 & & 1 & 2 \\
\hline Indeterminate & 6 & & 7 & 1 \\
\hline Malignant & 6 & 1 & 16 & \\
\hline
\end{tabular}

Histology results allow the reliability of the mammographic diagnoses to be assessed. The definitions used in this analysis are:

True-positive: Cancer diagnosed within one year after biopsy recommendation based on mammographic examination with abnormal findings,

True-negative: No known cancer detected within one year of mammographic examination with normal findings,

False-negative: Detection of cancer within one year of a mammographic examination with normal findings

False-positive: (a) No known cancer diagnosis within one year of a screening mammographic examination with abnormal findings (b) No known cancer diagnosis within one year after recommendation for biopsy or surgical consultation on the basis of a mammographic examination with abnormal findings (c) Benign findings at biopsy within one year after recommendation for biopsy or surgical consultations on the basis of a mammographic examination with abnormal findings.

Sensitivity: The percentage of all patients found to have breast cancer within one year of screening, correctly diagnosed as suggestive of breast cancer on the basis of mammographic findings.

Overall cancer detection rate: The number of cancers detected per 1,000 patients examined by mammography (Linver et al., 1995).

From Table 10 it can be seen that the indicators are within the limits expected from the literature. The histology identified one false-negative and there were 24 true-positives.

Table 10: Analysis of mammography audit data for 2001 at Princess Margaret Hospital together with "desirable goals"

\begin{tabular}{|l|c|c|}
\hline & $\begin{array}{c}\text { Achievements: } \\
\text { Histology } \\
\text { survey }\end{array}$ & $\begin{array}{c}\text { Desirable goal } \\
\text { (Linver } \text { et al, } \\
\text { 1995) }\end{array}$ \\
\hline $\begin{array}{l}\text { Positive predictive value, } \\
\text { based on abnormal findings } \\
\text { at screening examination }\end{array}$ & $11.0 \%$ & $5-10 \%$ \\
\hline $\begin{array}{l}\text { Positive predictive value } \\
\text { when biopsy performed }\end{array}$ & $65.0 \%$ & $25-40 \%$ \\
\hline Cancers found/1000 cases & $17.1 \%$ & $2-10^{\mathrm{a}}$ \\
\hline Recall rate & $15.4 \%$ & $\leq 10 \%^{\mathrm{a}}$ \\
\hline Specificity & $85 \%$ & $>90 \%$ \\
\hline Sensitivity & $96 \%$ & $>85 \%$ \\
\hline
\end{tabular}


Audit results for Princess Margaret Hospital based on the telephone study

The data collected from the telephone study were also used to estimate the performance of the mammography service and highlight areas which need further consideration.

Estimates for these values based on patients attending the Princess Margaret Hospital in 2001 are given in Table 11. Eighteen true-positives were detected by mammography and 61 false-positives, using definition (b).

Table 11: Analysis of mammography telephone study data for 2001 at Princess Margaret Hospital together with "desirable goals"

\begin{tabular}{|l|c|c|}
\hline & $\begin{array}{c}\text { Achievements: } \\
\text { Telephone } \\
\text { survey }\end{array}$ & $\begin{array}{c}\text { Desirable goal } \\
\text { (Linver et al, } \\
\text { 1995) }\end{array}$ \\
\hline $\begin{array}{l}\text { Positive predictive value, } \\
\text { based on abnormal findings } \\
\text { at screening examination }\end{array}$ & $15.4 \%$ & $5-10 \%$ \\
\hline $\begin{array}{l}\text { Positive predictive value } \\
\text { when biopsy or surgical } \\
\text { consultation recommended* }\end{array}$ & $18.6 \%$ & \\
\hline $\begin{array}{l}\text { Positive predictive value } \\
\text { when biopsy performed* }\end{array}$ & $32.1 \%$ & $25-40 \%$ \\
\hline Cancers found/1000 cases & $18.8 \%$ & $2-10$ \\
\hline Recall rate & $12.2 \%$ & $\leq 10 \%$ \\
\hline Specificity & $89.5 \%$ & $>90 \%$ \\
\hline Sensitivity & $100 \%$ & $>85 \%$ \\
\hline
\end{tabular}

*estimated

\section{TELEPHONE STUDY}

For patients who had had at least one mammogram in 2001, 1,439 were telephoned. These patients were asked about the outcome of their mammogram and other aspects related to breast cancer detection. They were asked about the frequency with which they performed breast self-examinations, the frequency that their doctor examined them, and their knowledge of the frequency and commencement of mammography screening.

Contact made with $77 \%$ of them (or 1,092 ) and contact was lost with $23 \%$. Each patient was telephoned six times before it was assumed that contact was lost.

The most common reasons for having a mammogram in 2001 were "routine" and doctor referral (Table 12). 


\begin{tabular}{|l|c|}
\hline & Percentage of respondents \\
Routine & 40 \\
\hline Doctor referral & 38 \\
\hline Self-referral & 17 \\
\hline Media articles & 3 \\
\hline Advised by friends & 2 \\
\hline
\end{tabular}

Three percent of patients claimed not to know the outcome of their mammogram, while one percent had tumors diagnosed (Table 13). Almost $40 \%$ of patients came at the request of doctors. When compared to percentage of patients who came as a result of the media or friends' advice, doctors are the highest outside influence to stimulate people to have mammograms.

Table 13: Initial outcome of mammograms in 2001, as stated by patients (1081 replies).

\begin{tabular}{|l|c|c|}
\hline & Number of patients & Percentage of respondents \\
\hline Normal & 908 & 84 \\
\hline Indeterminate & 128 & 12 \\
\hline Did not know & 35 & 3 \\
\hline Tumor (any type) & 10 & 1 \\
\hline
\end{tabular}

Patients were also asked for the final outcome resulting from the mammographic investigation: i.e. the outcome approximately one year after the radiologist's diagnosis. The radiologist's diagnosis was compared with that given by the patient as their final diagnosis after follow-up, Table 14. From Table 14 it can be seen that if a radiologist's diagnosis is "malignant", the probably of the patient saying they have a malignant cancer is $80 \%$. If the diagnosis is "indeterminate", the patient had about $9.5 \%$ chance of having a malignant cancer.

Table 14 does not include all the patients. Thirty-five patients did not know the outcome of the mammogram, including one who might have had a cancer. some patients thought that their initial outcome was "normal" yet the doctor's report was indeterminate. 
Table 14: Comparison of the frequency of doctor's diagnosis and the initial and final outcomes provided by the patient for patients having mammograms in 2001. (Number of patients)

\begin{tabular}{|c|c|c|c|c|c|c|}
\hline & & & \multicolumn{4}{|c|}{ Final Outcome } \\
\hline \begin{tabular}{|l|} 
Doctor's \\
Report \\
\end{tabular} & $\begin{array}{c}\text { Did not } \\
\text { Know }\end{array}$ & $\begin{array}{c}\text { Initial } \\
\text { Outcome }\end{array}$ & Normal & Benign & Malignant & Total \\
\hline Normal & 1 & Normal & 626 & & & 626 \\
\hline Benign & 18 & $\begin{array}{c}\text { Normal } \\
\text { Indeterminate }\end{array}$ & $\begin{array}{c}217 \\
25\end{array}$ & & 13 & $\begin{array}{c}217 \\
38\end{array}$ \\
\hline Indeterminate & 15 & $\begin{array}{c}\text { Normal } \\
\text { Indeterminate }\end{array}$ & $\begin{array}{l}23 \\
18\end{array}$ & $\begin{array}{c}11 \\
6\end{array}$ & $\begin{array}{l}1 \\
5\end{array}$ & $\begin{array}{l}35 \\
29\end{array}$ \\
\hline Malignant & 1 & $\begin{array}{c}\text { Indeterminate } \\
\text { Malignant }\end{array}$ & $\begin{array}{l}2 \\
1\end{array}$ & 1 & 11 & $\begin{array}{c}14 \\
1\end{array}$ \\
\hline Total & 35 & Total & 911 & 31 & 18 & 960 \\
\hline
\end{tabular}

Final outcome as reported by the patient

For 1,007 patients, the reason for having the mammogram was compared with the outcome of the examination (Table 15). Of the routine examinations, and those prompted by the media or friends, 4 out of 467 patients or 8.6 per 1,000 resulted in a malignant cancer being detected. Of the doctors' and self-referrals, 15 out of 538 patients or 28 per 1,000 were found to have malignant cancers. Thus, the odds ratio of being diagnosed with cancer was significantly higher $(\mathrm{p}<0.05)$ at $3.32(95 \%$ confidence limits: $1.09-10.07)$ if the patient was a doctor referral compared to a routine examination or prompted by the media or fiends.

Table15: Frequency of reasons for examination by final outcome of examination of 1,007 patients attending Princess Margaret Hospital for mammograms in 2001.

\begin{tabular}{|l|c|c|c|}
\hline \multirow{2}{*}{$\begin{array}{l}\text { Reason for } \\
\text { examination }\end{array}$} & Normal & $\begin{array}{c}\text { Fenign } \\
\text { tumor }\end{array}$ & $\begin{array}{c}\text { Malignant } \\
\text { tumor }\end{array}$ \\
\cline { 2 - 4 } & 18 & & 1 \\
\hline Advised by friends & 34 & 1 & 3 \\
\hline Routine examination & 402 & 8 & 8 \\
\hline Doctor referral & 345 & 13 & 7 \\
\hline Self referral & 155 & 10 & \\
\hline Other & 2 & & \\
\hline
\end{tabular}

Final outcome as reported by the patient.

Of the 19 patients who said that they had a malignant tumor, eight were doctor referrals, seven self-referrals and three arose from routine mammograms. Thus, $16 \%$ of the malignancies were detected because of routine screening.

Of the patients who had a tumor of some type, there was no statistical difference in the location of the tumors $(\mathrm{p}=0.30)$ between left, right, or both breasts (Table 16). 
Table16: Location of tumors (56 replies) in patients having mammograms in 2001 (56 replies).

\begin{tabular}{|l|c|}
\hline & Percentage of respondents \\
\hline Right breast & 43 \\
\hline Left breast & 30 \\
\hline Both breasts & 27 \\
\hline
\end{tabular}

Patients were asked about breast examinations. The modal times since the last breast self examination was within the last day (30\%) and the median time since last examination was approximately each week, $12 \%$ did not know when they last did it and $21 \%$ never examined their breasts.

The modal frequency of performing breast self-examination was everyday (24\%) and the median time was approximately every week. Twenty-four percent of respondents made irregular checks.

The modal time since the last doctor's examination of the breast was one year (18\%), Three percent said that the doctor had never examined their breasts and $9 \%$ did not know when the doctor had last examined their breasts, the median time since the last doctor's examination was five months. Sixty-two percent had their breasts examined by the doctor occasionally, and $30 \%$ on every visit.

Of those who had a mammogram in $2001,39 \%$ had one in 2002 , but two percent could not remember if they had had one in 2002. Those who did not have a mammogram in 2002 were asked why they had not had a subsequent one. The main reasons given are listed in Table 17. The modal reason for not having one was "no reason" (29\%) (636 replies). Eighteen percent said that they did not think it was necessary to return and $4 \%$ did not think that they had to return each year. Nine percent did not return because no one told them to return. Seven percent did not return as they found the experience uncomfortable. Expense was cited by $1.6 \%$ of respondents and $2.4 \%$ mentioned hours of operation of the service (which may or may not have been at Princess Margaret Hospital) as barriers to having a subsequent mammogram. 
Table 17: Main reason for 2001 mammography patients not returning for a mammogram in 2002.

\begin{tabular}{|c|c|c|c|}
\hline Reason & $\begin{array}{l}\text { Number of } \\
\text { patients }\end{array}$ & $\begin{array}{l}\text { Percentage of } \\
\text { all patients }\end{array}$ & $\begin{array}{c}\text { Percentage of } \\
\text { those not }\end{array}$ \\
\hline No reason & 187 & 17.2 & $\begin{array}{l}\text { returning } \\
29.4\end{array}$ \\
\hline Did not think it necessary & 111 & 10.2 & 17.5 \\
\hline Did not remember & 58 & 5.3 & 9.1 \\
\hline $\begin{array}{l}\text { No one told patient to have } \\
\text { another }\end{array}$ & 58 & 5.3 & 9.1 \\
\hline Uncomfortable & 44 & 4.0 & 6.9 \\
\hline No time & 27 & 2.5 & 4.3 \\
\hline Other reasons & 26 & 2.4 & 4.1 \\
\hline $\begin{array}{l}\text { Patient did not think they } \\
\text { had to return each year }\end{array}$ & 24 & 2.2 & 3.8 \\
\hline $\begin{array}{l}\text { Unable to make an } \\
\text { appointment }\end{array}$ & 17 & 1.6 & 2.7 \\
\hline Hours of service & 15 & 1.4 & 2.4 \\
\hline Dr. said every two years & 11 & 1.0 & 1.7 \\
\hline Expense & 10 & 9.9 & 1.6 \\
\hline Too young & 8 & 0.7 & 1.3 \\
\hline $\begin{array}{l}\text { Unable to get an } \\
\text { appointment }\end{array}$ & 8 & 0.7 & 1.3 \\
\hline III & 7 & 0.6 & 1.1 \\
\hline Long appointment time & 5 & 0.5 & 0.8 \\
\hline Planned to have one in 2003 & 4 & 0.4 & 0.6 \\
\hline Keep putting it off & 3 & 0.3 & 0.5 \\
\hline Pregnant & 3 & 0.3 & 0.5 \\
\hline $\begin{array}{l}\text { Did not get previous results } \\
\text { so did not return }\end{array}$ & 2 & 0.2 & 0.3 \\
\hline Dr. said every three years & 2 & 0.2 & 0.3 \\
\hline $\begin{array}{l}\text { Told by doctor to have one } \\
\text { in } 2001\end{array}$ & 2 & 0.2 & 0.3 \\
\hline $\begin{array}{l}\text { Did not want to know if } \\
\text { anything was wrong }\end{array}$ & 1 & 0.1 & 0.2 \\
\hline Have an appointment booked & 1 & 0.1 & 0.2 \\
\hline Machine was not working & 1 & 0.1 & 0.2 \\
\hline Total replying & & & 635 \\
\hline Total contacted & & 1088 & \\
\hline
\end{tabular}

Patients were asked about the frequency with which they should have a mammogram and at what age they should start. Sixty-one percent (of 1094 replies) thought they should have a mammogram each year, and $15 \%$ every six months. Ten percent did not know how often they should have a mammogram. Thirty- 
one percent (of 1089 replies) thought that females should start having mammograms in their 30s, and $29 \%$ in their 20's. Seven percent thought that they should start after onset of menstruation and $12 \%$ did not know.

\section{LOCATION EFFECTS AND RISK OF BREAST CANCER}

The proportion of women being diagnosed with breast cancer, living in different areas of New Providence based upon telephone exchange was noted. Telephone exchanges are broad indicators of where people live and so can be associated with location differences. Although the percentages of patients diagnosed with breast cancer varies from $2.46 \%$ to nil, the numbers involved are too small to detect statistically significant differences in odds ratios associated with location (Table 18).

Table 18: Percentage on patients diagnosed with breast cancer at the Princess Margaret Hospital classified by telephone exchange.

\begin{tabular}{|l|c|c|c|}
\hline Exchange* & $\begin{array}{c}\text { Number diagnosed } \\
\text { with breast Cancer }\end{array}$ & $\begin{array}{l}\text { Total numer } \\
\text { of Patients }\end{array}$ & $\begin{array}{l}\text { \% age with } \\
\text { breast cancer }\end{array}$ \\
\hline Central Nassau & 37 & 1504 & 2.46 \\
\hline Soldier Road & 13 & 544 & 2.39 \\
\hline South Central & 12 & 606 & 1.98 \\
\hline Pinewood & 5 & 356 & 1.40 \\
\hline Camperdown & 8 & 583 & 1.37 \\
\hline Lyford Cay, & 0 & 126 & 0 \\
\hline Delaport, P.I. & & & \\
\hline
\end{tabular}

*As specified in Bahamas Telecommunication Company (n.d.).

In 2000, New Providence housed $69 \%$ of the female population aged 40 or more (Department of Statistics, 2002), and between 1994 and 2000, 83\% of deaths due to breast cancer were reported from New Providence, (Health Information and Research Unit, 2001a). This indicates that women in New Providence have a significantly higher $(\mathrm{p}<0.05)$ odds ratio of about $2.1(95 \%$ confidence limits:1.4-3.1) of dying of breast cancer, than women on other Bahamian islands. Age specific rates of deaths due to breast cancer showed that the rates in New Providence were close to three times that in all the other islands (Heath Information and Research Unit, 2003b), Figure 2. Standardized mortality ratios (SMR) (100xobserved deaths/expected deaths) for three age groups (under 45, 45-64 and 65+) in the period 1994 to 2000, which compared breast cancer deaths in New Providence to those on all the other islands confirmed this observation, Table 19 (Heath Information and Research Unit, 2003b). In each of the seven years, the SMR was greater than one, which indicates that there were more deaths due to breast cancer in New Providence than expected. 


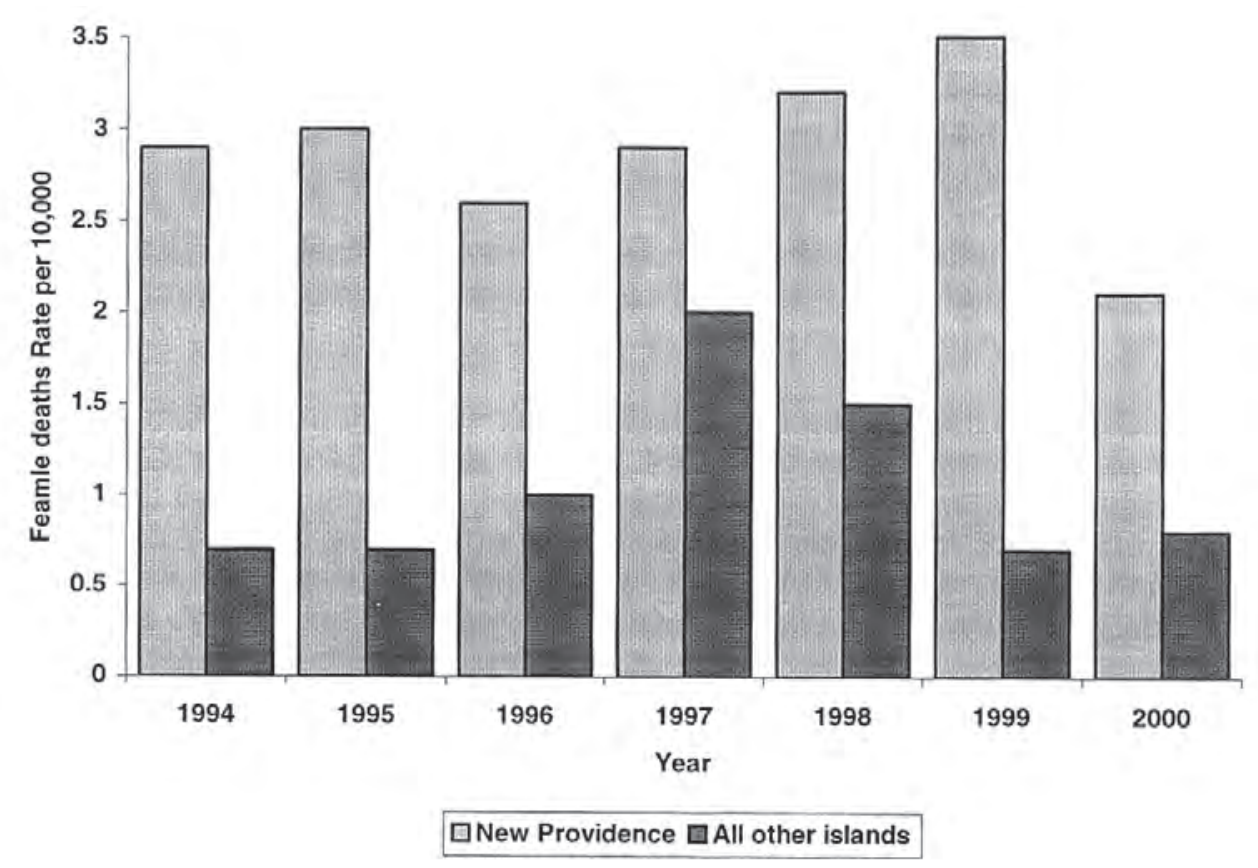

Figure 2: Rates (age adjusted) per 10,000 females of deaths due to breast cancer, 1994-2000, for New Providence and all other Bahamian islands.

Table 19: Age adjustment (age standardization) using indirect adjustment for standardized mortality ratios (SMR). Female breast cancer deaths in New Providence as compared to all other islands, 1994-2000.

\begin{tabular}{|l|l|}
\hline Year & SMR \\
\hline 1994 & 1.62 \\
\hline 1995 & 1.65 \\
\hline 1996 & 1.58 \\
\hline 1997 & 1.38 \\
\hline 1998 & 1.59 \\
\hline 1999 & 1.51 \\
\hline 2000 & 1.16 \\
\hline
\end{tabular}

Source: (Health Information and Research Unit, 2003b).

\section{DISCUSSION}

Primary aim of the study was to report a mammography audit at Princess Margaret Hospital. This audit, which used both histology and patient followup via a telephone study, indicated that the standard of the mammography service offered at the Hospital meets acceptable standards.

The study suggests that mammographic examinations are finding proportionately more cancers than might be expected from other studies as referrals are relatively late and relatively more diagnostic that screening mammograms are done. The cancer rate per 1000 is therefore higher than that found in other studies. The higher positive predictive values when biopsy is recommended probably arises from relatively fewer patients having biopsies. Proportionately more patients are recalled than in other populations and this might be justifi- 
able given so many cancers being found. The specificity being over $90 \%$ indicates that the skill of the doctors is within acceptable limits. The difference in sensitivity found using the telephone study and histology data reflects the fact that, the false-positive patient identified via histology could not be contacted by telephone.

The audit indicated that data recording associated with patient's records can be improved. The fact that patients did not always know or incorrectly knew the outcome of their mammogram points to the need for better communication between patient and doctor. This is a shared responsibility. Although the telephone would appear to be the obvious method of communication, many telephones do not work (Fielding \& Samuels, 2002) and actually being able to find a patient by telephone can be difficult.

The telephone study indicated that one in four patients can be lost to follow-up within a year. Studies from The Bahamas show that both postal (Vanderpool \& Fielding, 2003) and telephone surveys (Vanderpool, 2002 and Fielding \& Samuels, 2002) can have problems in eliciting responses from target groups. Even in this study, a patient who claimed not to know the outcome of the mammogram and had been diagnosed with a possible malignancy, could not be contacted some days later after the survey forms had been examined. This incident shows the difficulty and importance of communicating with patients. Therefore, once the patient is in the Department or office, medical staff must try and do everything associated with the reason for visit at the same time. The patient has to be educated to contact the Hospital concerning any outstanding matters. The onus unfortunately still is with patients to ensure that they get their diagnosis and follow-up as Hospital resources and tracking systems are unlikely to guarantee $100 \%$ follow-up. Clinicians must educate and talk with patients when they see them. One way of encouraging patients to get results could be to issue cards with contact numbers and names of relevant hospital staff who will be familiar with the patients' files. The cards could also indicate the time frame within which the results should be ready.

Too many patients were unaware of important factors associated with breast examinations and routine screening. These responses again show the need for further education and are in line with those found in other Bahamian studies on breast self examination (Dean, 1985 and Mackey, 2001).

Factors such as a family history of breast cancer or previous mastectomy were seen to be associated with an increased risk of contracting breast cancer. It is important that these higher risk groups are educated as a matter of priority.

The frequency of reasons as to why patients did not have routine mammograms showed that expense was not a major concern for the population included in this study. This finding shows that the Hospital might have room for maneuver if it wanted to increase the cost of a mammogram. The real reasons why patients are not returning seem to be: (a) lack of education and (b) regular mammograms are not considered essential.

The reasons for not returning show that the doctor has a major role in: (a) sending patients for mammograms initially, i.e. $36-38 \%$ of patients came for mammograms as doctor referrals, and a major reason for patients to return. The importance of the doctor's role in encouraging mammography screen- 
ing highlights the fact that doctors need to be educated or re-educated, so that they encourage routine screening at an early age of higher risk patients. Doctors must be cautious and not wait for the patient to present with a complaint before referring her for a mammogram. The fact that so many patients had no clear reason, as opposed to an excuse, for not returning, shows that patients are yet to appreciate the importance of routine screening. It is easy to interpret the results as indicating that patients only present when they have a complaint, which is clearly undesirable.

Unless doctors encourage patients to participate in preventive practices, the Hospital can expect to play only a predominantly diagnostic role in breast cancer. The failure of patients to have routine mammograms is seen in the high incidence of breast cancer at the histology stage (Table 10). The data indicated that many histology patients may be having mammograms outside of Princess Margaret Hospital or not at all. This may suggest that once patients present with a lump clinicians feel that the patient must have the lump removed in exclusion of a mammogram. However, this approach does not help patients who may have multifocal cancers. The study was not able to explain why this should be.

This study also provides useful baseline data so that changes in mammography practices and usage can be assessed. In particular, the effects, on patient knowledge can now be assessed.

While no variation in breast cancer rates were detected within New Providence this may be a result of the small sample, rather the absence of differences. It was noted that New Providence had a disproportionate number of all breast cancer malignancies reported in The Bahamas. While there are many interpretations for this finding, the observations in Table 19 suggest that further studies are needed to explain these differences in cancer risks.

It is hoped that this study will stimulate further research in this important area of healthcare.

\section{ACKNOWLEDGMENTS}

Dr Z. Farley, Dr. T. Pratt Dr J. Lowe, for assisting in the data collection. Miss Roybn Lynes entered the data from the telephone study. The Research Unit at The College of The Bahamas assisted in the analysis and presentation of the data. We are grateful to Miss Nanika Braithwaite of the Heath Information and Research Unit for calculating the SMRs and providing national data on cancers.

\section{REFERENCES}

Altman, D. G. (1991). Practical statistics for medical research. Washington DC: Chapman \& Hall/CRC

American Cancer Society (2004). Cancer Reference Information. What are the risk factors for breast cancer? Retrieved 17th November 2004 from http:// www.cncer.org/docroot/CRI/content/CRI 24 2X What are _the_risk_ factors_for_breast_cancer. 
Bahamas Telecommunication Company (n.d.). Bahamas code routing guide. Nassau: Bahamas Telecommunication Company.

BBC (2001). Nightshift link to breast cancer. 10th January. Retrieved 11th February 2003 from http://news.bbc.co.uk/2/low/health/1108590.stm.

Dean, J. G. (1985). Breast self-examination practice among Bahamian women: government clinic clientele. North Carolina: M.Sc. thesis, University of North Carolina.

Department of Statistics (2002). Report of the 2000 census of populations and housing. Nassau: Ministry of Economic Development.

Early breast screening 'saves lives' (2003). Retrieved 25th April 2003 from http://newsvote.bbc.co.uk/mpapps/pagetools/print/news.bbc.co.uk/1/ hi/health/2972397.stm.

Fielding, W. J. \& Samuels, D. (2002). Preliminary observations on the telephone survey as a research tool in New Providence. College of The Bahamas Research Journal XI 4-11.

Health Information and Research Unit (2001a). [Leading cause of death, 2000 all Bahamas]. Unpublished raw data.

Health Information and Research Unit (2001b). [The ten leading causes of death of females, all Bahamas, 2000]. Unpublished raw data.

Health Information and Research Unit (2001c). [Number of reported new cases of malignant neoplasms (Cancer): Age 65 years and older by gender, Princess Margaret Hospital, 2001]. Unpublished raw data.

Health Information and Research Unit (2002a). [Number of reported new cases of malignant neoplasms (Cancer): Age 45-64 years and older by gender, Princess Margaret Hospital, 2001]. Unpublished raw data.

Health Information and Research Unit (2002b). [Number of reported new cases of malignant neoplasms (Cancer at Princess Margaret Hospital, 2000-2001]. Unpublished raw data.

Heath Information and Research Unit (2003a). [Age adjustment (Age standardizations) using indirect adjustment for SMR female breast cancer deaths in New Providence as compared to all Bahamas 1994-2000]. Unpublished raw data.

Heath Information and Research Unit (2003b). [Number and age specific rates of death due to breast cancer 1994-2000 New Providence, all other (Family) islands, and all Bahamas]. Unpublished raw data.

Life Force (2003). The Cancer Society of The Bahamas. Nassau.

Linver, M. N. (1997). The mammography audit. Unpublished teaching hand66 out. 
Linver, M. N., Osuch, J. R., Brenner, R. J. \& Smith, R. A. (1995). The mammography audit: A primer for the Mammography Quality Standards Act (MQSA). American Journal of Radiology; 165: 19-25.

Mackey, K. (2001). The beliefs and attitudes of Bahamian women concerning prevention and detection of breast cancer. M.S.N. thesis, Barry University, Miami Shores.

Shiels, M. (2002). California's breast cancer blight. 30th January. Retrieved 11th June 2003 from http://news/bbc.co.uk/2/hi/science/nature/1791727. stm.

Vanderpool, J. (2002). Reflections on public opinion polling in The Bahamas: Academic research perspectives. Paper presented at the April Research Edge Forum. The College of The Bahamas at Nassau.

Vanderpool, J. \& Fielding, W. J. (2003). The postal survey as a research tool in New Providence. College of The Bahamas Research Journal XII: 46-55. .

What Bahamian women should know about Breast Cancer (2003). The Nassau Guardian, 15th May. Retrieved 19th May 2003 from http://archive. nassauguardian.net/archive detail.php?archiveFile $=. / \mathrm{pubfiles} / \mathrm{nas} /$ archive/2003/May/15/SocialCommunityNews/18108.xml\&start=0\&num $\underline{\text { Per}=20 \& k e y w o r d=\text { mammography\&sectionSearch }=\& \text { begindate }=1 \% 2 \mathrm{~F} 1 \% 2}$ F2002\&enddate $=12 \% 2 F 1 \% 2 F 2003 \&$ authorSearch=\&IncludeStories $=1 \& p u$ $\underline{\text { bsection }=\& \text { page }=\& \text { IncludePages }=\& \text { IncludeImages }=\& \text { mode }=\text { allwords } \& \text { arc }}$ hive_pubname=Nassau+Guardian\%0A\%09\%09\%09.

Dr. Solange Payne-Fielding is a consultant radiologist at the Princess Margaret Hospital, Nassau, The Bahamas; a post she has held since 1997. Previously, she was lecturer at the University of the West Indies, Mona and she is currently an Associate Lecturer, at its Bahamas Campus.

Leander Farrington is a third-year medical student at the University of the West Indies, Mount Hope, Trinidad \& Tobago Campus. 